\title{
Staphylococcus aureus but not Staphylococcus epidermidis can acquire iron from transferrin
}

\author{
J. A. Lindsay, ${ }^{1}$ T. V. Riley ${ }^{2}$ and B. J. Mee' \\ Author for correspondence: B. J. Mee. Tel: +619346 2286. Fax: +6193462912.
}

\author{
1 Department of \\ Microbiology, The \\ University of Western \\ Australia, Queen Elizabeth \\ II Medical Centre, \\ Nedlands 6009, Western \\ Australia, Australia \\ 2 Department of Clinical \\ Microbiology, Sir Charles \\ Gairdner Hospital, Queen \\ Elizabeth II Medical \\ Centre, Nedlands 6009, \\ Western Australia, \\ Australia
}

\begin{abstract}
Staphylococci grow and cause infection under the iron-restricted conditions found in vivo. They therefore must possess mechanisms to obtain iron for metabolism from this environment. To determine if staphylococci can extract iron bound to human transferrin, we labelled transferrin with ${ }^{55} \mathrm{Fe}$ and performed uptake assays on cells grown in iron-restricted and iron-plentiful conditions. Growing cultures of Staphylococcus aureus NCTC 8532 could take up radioactive iron during mid- to late-exponential phase of growth. This process was iron-regulated and did not require direct contact between the cell and the labelled transferrin. Siderophore production was detected during this phase, but reductase or protease activity was not. S. epidermidis ATCC 14990 could not access ${ }^{55} \mathrm{Fe}$ bound to transferrin, nor did this isolate produce siderophore, reductase or protease. This difference in the ability to acquire iron bound to transferrin may contribute to the increased virulence of $S$. aureus when compared to $S$. epidermidis.
\end{abstract}

Keywords: staphylococci, iron, transferrin, siderophore

\section{INTRODUCTION}

Iron is essential for the growth of virtually all living cells. Although intracellular iron is plentiful in host tissues, it is not readily available extracellularly as it is bound to specific iron-binding proteins, such as transferrin. Transferrin is found in serum and lymph and has an extremely high affinity for ferric iron. It is normally only $30 \%$ saturated, allowing it to scavenge iron and transport it around the body. For pathogenic bacteria to multiply in host tissues and cause infection, they must possess efficient mechanisms for the uptake of iron, which may include the uptake of iron bound to transferrin (for reviews see Williams \& Griffiths, 1992; Wooldridge \& Williams, 1993).

Many micro-organisms produce siderophores, compounds of low molecular mass with high affinities for iron, which compete with transferrin and other iron sources in vivo (Wooldridge \& Williams, 1993). Organisms such as Neisseria meningitidis, $N$. gonorrboeae and Haemopbilus influenzae express specific transferrin receptors on their cell surfaces which bind and remove the iron (Williams \& Griffiths, 1982). Some intracellular

Abbreviations: CAS, chrome azurol S; CoNS, coagulase-negative staphylococci; SSD-OFe, staphylococcal siderophore detection medium containing less than $0.05 \mu \mathrm{M}$ iron; SSD-gC, SSD-OFe prepared without glucose or Casamino acids. pathogens such as Listeria monocytogenes produce ferric reductases, which reduce iron from the $\mathrm{Fe}^{3+}$ to the $\mathrm{Fe}^{2+}$ state and decrease its affinity for transferrin (Cowart \& Foster, 1985). Proteolytic cleavage of transferrin resulting in the disruption of iron-binding sites may also be important (Williams \& Griffiths, 1992).

Staphylococci are important clinical pathogens. S. aureus causes a range of nosocomial and community-acquired pyogenic infections and toxin-related diseases. The coagulase-negative staphylococci (CoNS), including the major pathogen Staphylococcus epidermidis, are considered less pathogenic but are a frequent cause of infection in immunocompromised patients, particularly those with indwelling medical devices. Despite their medical importance, little is known of the ability of staphylococci to scavenge iron.

Schade (1963) showed that isolates of Stapbylococcus aureus could grow in human serum in vitro. Growth was enhanced if excess iron was added, suggesting uptake of some transferrin-bound iron, but not enough to maintain maximal growth. S. albus isolates (CoNS) were not able to grow in serum but grew well if iron was added, indicating a poor iron-scavenging system.

In a simple plate assay, Marcelis et al. (1978) showed that the growth of $S$. aureus was not inhibited by the presence of transferrin while the growth of $S$. epidermidis was inhibited, albeit only by the highest concentration tested, 
approximately 46-fold greater than the concentration found in human serum. They concluded that $S$. aureus was able to access transferrin-bound iron, while $S$. epidermidis could not, and that this might be considered a virulence factor.

More recently, Brock et al. (1991) showed that S. aureus NCTC 8532 and a clinical isolate of $S$. epidermidis utilized only a small proportion of radioactive iron bound to transferrin, while taking up a larger proportion of radioactive iron released by the K562 erythroleukaemic cell line. In this case, transferrin was separated from the bacterial cells by a dialysis membrane, but it was not determined whether staphylococci could access iron bound to transferrin via a specific cell surface receptor such as that described for meningococci, gonococci and Haemophilus species. Recently, a $42 \mathrm{kDa}$ transferrin-binding protein expressed on the surface of $S$. aureus and $S$. epidermidis and some other CoNS has been described (Modun et al., 1994), although its role in the uptake of iron has not yet been determined.

S. aureus and some CoNS produce siderophores that react with the universal chrome azurol S (CAS) assay of Schwyn \& Neilands (1987) (Meiwes et al., 1990; Courcol et al., 1991; Lindsay \& Riley, 1994). Two siderophores, staphyloferrin A and staphyloferrin B, have been isolated and chemically characterized (Meiwes et al., 1990; Drechsel $e t$ al., 1993) although their relative importance in scavenging iron is unknown. Lindsay \& Riley (1994) showed $S$. aureus isolates produced high levels of CAS activity which was not influenced by the precursors of staphyloferrin $A$ and $B$, suggesting the CAS activity was due to the presence of uncharacterized siderophores. CoNS isolates produced significantly less CAS activity, although the production of staphyloferrin $A$ and $B$ was common. Some CoNS under iron-restricted conditions produced citrate, which may function like a siderophore. Citrate was not detected in $S$. aureus cultures.

The purpose of our study was to determine if staphylococci could take up ${ }^{55} \mathrm{Fe}$ bound to transferrin and, if so, whether this was achieved using: (i) a siderophore; (ii) direct cell contact between the transferrin and the cell surface; (iii) a reductase to reduce the affinity of transferrin for iron; or (iv) a protease capable of cleaving the transferrin molecule.

\section{METHODS}

Bacterial strains and growth media. S. aureus NCTC 8532 (ATCC 12600) and S. epidermidis ATCC 14990 were grown in SSD-0Fe medium (Lindsay \& Riley, 1994). Briefly, SSD is a defined medium, apart from the use of Casamino acids as the nitrogen source. When treated with Chelex 100 the iron concentration is reduced to less than $0.05 \mu \mathrm{M}$ (SSD-0Fe). The medium is low in phosphates $(2 \mathrm{mM})$ and devoid of citrate, making it compatible with the CAS assay for the detection of siderophores (Schwyn \& Neilands, 1987). SSD-0Fe was supplemented with $0.5 \mu \mathrm{M}$ or $10 \mu \mathrm{M} \mathrm{FeCl}, 6 \mathrm{H}_{2} \mathrm{O}$ (SSD- $0.5 \mathrm{Fe}$ or SSD-10Fe) as required. $S$. aureus grows well in SSD-0Fe (iron-restricted) but $S$. epidermidis requires $0.5 \mu \mathrm{M}$ Fe for growth (iron-restricted) and $10 \mu \mathrm{M} \mathrm{Fe}$ (iron-plentiful) for maximal growth (Lindsay \& Riley, 1994).
Labelling of transferrin with ${ }^{55} \mathrm{Fe}$. Human transferrin $(10 \mathrm{mg}$; Sigma) was dissolved in $400 \mu \mathrm{l}$ Tris/bicarbonate buffer $(20 \mathrm{mM}$ $\mathrm{NaHCO}_{3}, 40 \mathrm{mM}$ Tris, pH adjusted to 7.4 with $\mathrm{HCl}$ ) and then dialysed against buffer overnight. A solution of $143 \mu \mathrm{M}$ nitrilotriacetic acid and $143 \mu \mathrm{M}^{55} \mathrm{FeCl}_{3}$ (Amersham; $1.04 \mathrm{MBq}$ ) in $600 \mu \mathrm{l}$ buffer was equilibrated for $30 \mathrm{~min}$. The two solutions were mixed, allowed to equilibrate for $30 \mathrm{~min}$, and then dialysed against $200 \mathrm{ml}$ buffer overnight.

To determine the concentration of unbound iron in the solution, the sample was centrifuged in a Centricon 10 filter at $5000 \mathrm{~g}$ for $15 \mathrm{~min}$. The radioactivity of a sample of the filtrate compared to a sample of the uncentrifuged solution demonstrated that $0 \cdot 184 \%$ of the radioactivity in the sample was unbound. Using radioactivity counts, it was estimated that $25 \%$ of the transferrin binding sites were occupied with ${ }^{55} \mathrm{Fe}$. Labelled transferrin was run on PAGE gels and appeared as a $79 \mathrm{kDa}$ band. No breakdown products or heterogeneity of the protein were observed (data not shown).

Uptake of ${ }^{55} \mathrm{Fe}$ bound to transferrin by non-growing cell suspensions ( $30 \mathrm{~min})$. Several colonies from a blood agar plate were suspended in SSD-0Fe to an $\mathrm{OD}_{450}$ of $0 \cdot 15$, inoculated $1: 100$ into iron-restricted media (SSD-0Fe for $S$. aureus and SSD- $0.5 \mathrm{Fe}$ for $S$. epidermidis) and incubated overnight with shaking at $37^{\circ} \mathrm{C}$. This inoculum was diluted $1: 10$ in either ironrestricted or iron-plentiful medium. Cultures $(10 \mathrm{ml})$ were incubated in plastic $30 \mathrm{ml}$ bottles with shaking at $37^{\circ} \mathrm{C}$ until the cells reached mid-exponential phase $\left(\mathrm{OD}_{450}\right.$ approximately 0.3$)$. This took approximately $5 \mathrm{~h}$ for $S$. aureus, $6 \mathrm{~h}$ for $S$. epidermidis in iron-plentiful medium and $7 \mathrm{~h}$ for $S$. epidermidis in ironrestricted medium. Cultures were adjusted to a turbidity equivalent to $1 \times 10^{8}$ cells $\mathrm{ml}^{-1}$, and $10 \mathrm{ml}$ volumes were washed twice in SSD prepared without glucose or Casamino acids (SSD-gc), and resuspended in $0.8 \mathrm{ml} \mathrm{SSD-gc.} \mathrm{Cell} \mathrm{suspensions}$ were used in uptake studies within 20 min of preparation.

Labelled transferrin solution $(5-10 \mu \mathrm{l})$ was mixed with 190-195 $\mu \mathrm{l} \mathrm{SSD-0Fe} \mathrm{or} \mathrm{supernatant} 30 \mathrm{~min}$ prior to use. Supernatant was that from $24 \mathrm{~h}$ cultures of cells grown in ironrestricted or iron-plentiful conditions and siderophore activity of the supernatant was determined using the CAS assay as previously described (Lindsay \& Riley, 1994). This assay detected chelating activity greater than $3 \mu \mathrm{M}$ desferrioxamine mesylate (Ciba-Geigy) equivalents. The transferrin mixture was added to the cell suspension and $100 \mu \mathrm{l}$ samples taken at various time intervals were spotted onto cellulose nitrate membranes with a pore size of $0.22 \mu \mathrm{m}$ (Sartorius) in a vacuum filter apparatus and washed twice with $2 \mathrm{ml} 0.5 \%$ thioglycollic acid. The membranes had previously been blocked by soaking for $30 \mathrm{~min}$ in $1 \%(\mathrm{w} / \mathrm{v})$ gelatin in T-TBS $(20 \mathrm{mM}$ Tris, $0.5 \mathrm{M}$ $\mathrm{NaCl}, 0.05 \%$ Tween-80, $\mathrm{pH} \mathrm{7.4)}$ and then washed with SSD-gc containing $100 \mu \mathrm{M}$ iron. The membranes were air dried, mixed with $5 \mathrm{ml}$ of Filter-Count scintillant (Packard) and counted on a Packard Tri-Carb 1900CA liquid scintillation analyser. The amount of activity associated with the cells on the filter was compared to the amount of activity in a $100 \mu \mathrm{l}$ sample, and expressed as a percentage. All experiments were performed at least three times.

Uptake of ${ }^{55} \mathrm{Fe}$ bound to transferrin by growing cells $(8 \mathrm{~h})$. Overnight cultures of $S$. aureus and $S$. epidermidis were prepared as described above and diluted 1:10 in either iron-restricted or iron-plentiful medium. In these experiments, S. epidermidis overnight cultures were diluted in SSD-OFe rather than SSD$0.5 \mathrm{Fe}$. Labelled transferrin was added directly to the plastic culture bottles $(10 \mu \mathrm{l}$ per $10 \mathrm{ml}$ culture), or suspended in a dialysis membrane and added to the culture. This was to determine if direct contact between the staphylococcal cells and 
transferrin was required for uptake. In some control experiments, pieces of dialysis membrane without transferrin were added to the growth cultures. Cultures were incubated with shaking at $37^{\circ} \mathrm{C}$. At $45 \mathrm{~min}$ intervals, $100 \mu \mathrm{l}$ samples were spotted onto nitrocellulose membranes and their radioactivity measured as described above; $\mathrm{pH}$ was measured by spotting samples onto $\mathrm{pH}$ strips. Growth was determined by measuring $\mathrm{OD}_{620}$ and chelating activity was measured by the CAS assay (Lindsay \& Riley, 1994). The concentration of transferrin used was not detectable and did not interfere with the CAS assay measurements. Growth and chelating activity of cells in culture tubes without transferrin were also measured. All experiments were performed at least three times.

Reductase assay. Reductase activity of $8 \mathrm{~h}$ cultures was measured using the bathophenanthroline-disulfonic acid method of Cowart \& Foster (1985) with some modifications. Transferrin was labelled as described above, except that $50 \mathrm{mg}$ transferrin, and $0.8 \mathrm{mM}$ nitrilotriacetic acid and $\mathrm{FeCl}_{3} \cdot 6 \mathrm{H}_{2} \mathrm{O}$, were used to make up the $1.5 \mathrm{ml}$ of stock solution. Stock transferrin solution was used at a concentration of $33.5 \mu \mathrm{l} \mathrm{ml}^{-1}$. The buffer used in the assay was $20 \mathrm{mM}$ Tris/ $\mathrm{HCl}, \mathrm{pH} 7 \cdot 4$. The positive control was a clinical isolate of Listeria monocytogenes grown in brain heart infusion dialysate treated with $\mathrm{CaCl}_{2}$ (Cowart et al., 1980).

Cleavage of transferrin by staphylococcal proteases. ${ }^{55} \mathrm{Fe}$ transferrin $(2 \mu \mathrm{l})$ was mixed for $2 \mathrm{~h}$ at $37^{\circ} \mathrm{C}$ with $22 \mu \mathrm{l}$ supernatant from $8 \mathrm{~h}$ cultures of $S$. aureus and $S$. epidermidis grown in either iron-restricted or iron-plentiful medium. Controls of SSD-0Fe with the $\mathrm{pH}$ adjusted to 7.4 or 5.3 mixed with ${ }^{55} \mathrm{Fe}$-transferrin were included. Samples were run on nondenaturing PAGE gels (mini-Protean, Bio-Rad), stained using the method of Neuhoff et al. (1988) without fixation, and compared to detect transferrin breakdown products.

\section{RESULTS}

\section{S. aureus}

In short-term ( $30 \mathrm{~min}$ ) uptake experiments using washed exponential-phase $S$. aureus NCTC 8532 cells grown in iron-restricted medium and resuspended in fresh SSD-0Fe medium, an immediate association of the ${ }^{55} \mathrm{Fe}$-transferrin with the cells was seen (Fig. 1). There was no increase in the amount of cell-associated radioactivity with time. To determine if siderophore was required for uptake to be detected, transferrin was mixed with supernatant from a 24 h culture of $S$. aureus grown in SSD-0Fe. Uptake of ${ }^{55} \mathrm{Fe}$ by cells occurred (Fig. 1). This supernatant had CAS activity equivalent to $7 \cdot 0 \pm 2 \cdot 0 \mu \mathrm{M}$ desferrioxamine equivalents and a $\mathrm{pH}$ of 5.4 . However, uptake did not occur if the $\mathrm{pH}$ of the supernatant was adjusted to $7 \cdot 4$ (CAS activity equivalent to $6.7 \pm 1.6 \mu \mathrm{M}$ desferrioxamine). When supernatant from an iron-plentiful culture was used (pH 5.3, no CAS activity) uptake was detected, but when the $\mathrm{pH}$ was adjusted to $7 \cdot 4$ (no CAS activity), no uptake ocurred (data not shown). S. aureus cells grown in iron-plentiful conditions showed a similar response to the iron-restricted cells (data not shown). Since we could not demonstrate $\mathrm{pH}$-independent uptake of ${ }^{55} \mathrm{Fe}$ bound to transferrin over $30 \mathrm{~min}$, we looked for uptake by growing cells over $8 \mathrm{~h}$.

Growth of $S$. aureus was not affected by the small amount of labelled transferrin added. However, cell yield was

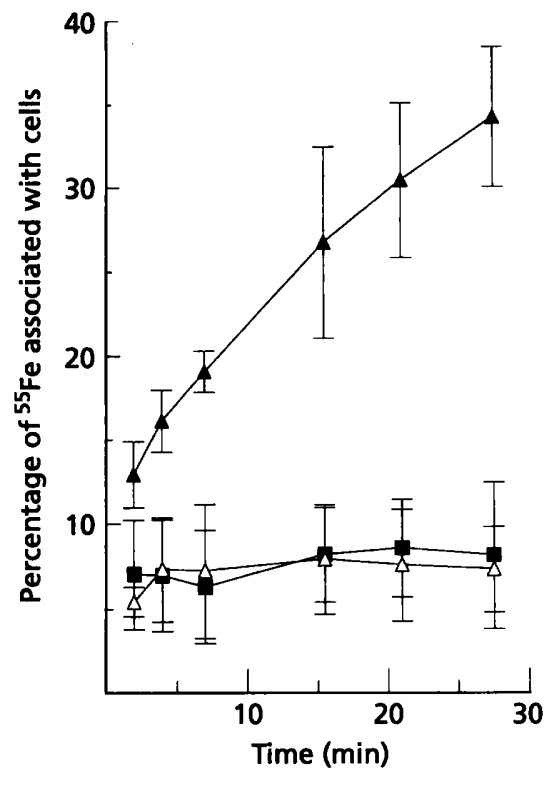

Fig. 1. Uptake of ${ }^{55} \mathrm{Fe}$ bound to transferrin by exponentialphase cells of S. aureus NCTC 8532 over $30 \mathrm{~min}$ with: SSD-OFe added $(\square)$; supernatant from a $24 \mathrm{~h}$ iron-restricted culture of $S$. aureus ( $\mathrm{pH}$ 5.4, 7.0 $\mu \mathrm{M}$ desferrioxamine equivalents) added ( $\Delta$ ); or supernatant from a $\mathbf{2 4} \mathrm{h}$ iron-restricted culture of $S$. aureus with $\mathrm{pH}$ adjusted (pH 7.4, 6.7 $\mu \mathrm{M}$ desferrioxamine equivalents) added $(\Delta)$. Data shown are the mean and standard deviation of three experiments.

increased slightly by the presence of dialysis membrane, so dialysis membrane with or without transferrin was added to all $S$. aureus cultures in the series of $8 \mathrm{~h}$ growth experiments. In these experiments, as with the $30 \mathrm{~min}$ experiments, radioactivity was associated with the cells immediately. The level of ${ }^{55} \mathrm{Fe}$ associated with the cells remained constant until mid- to late-exponential phase, when the cell-associated ${ }^{55} \mathrm{Fe}$ began to increase (Fig. 2a). During this time, the $\mathrm{pH}$ decreased from 8.4 to 6.8 . If the experiment continued beyond $8 \mathrm{~h}$, the $\mathrm{pH}$ fell very quickly, and caused iron to dissociate from transferrin. Siderophore was detectable at low levels during the lag phase (presumably this was carried over from precultures), but production increased immediately prior to when the increase in ${ }^{55} \mathrm{Fe}$ uptake was observed.

When $S$. aureus was grown in iron-restricted medium with the labelled transferrin inside the dialysis membrane, growth was not affected (Fig. 2b). The amount of radioactivity associated with the cells was much lower initially, approximately $1 \%$. This increased slowly until mid-exponential phase, where the maximum increase occurred, although it did not reach the same level as when the transferrin had direct contact with the cells. Siderophore production was unaffected by the lack of contact with transferrin.

When $S$. aureus cells were grown in iron-plentiful medium with direct access to transferrin, growth was relatively unaffected (Fig. 2c). Radioactivity associated with the cells was high initially, with a slight increase towards the 

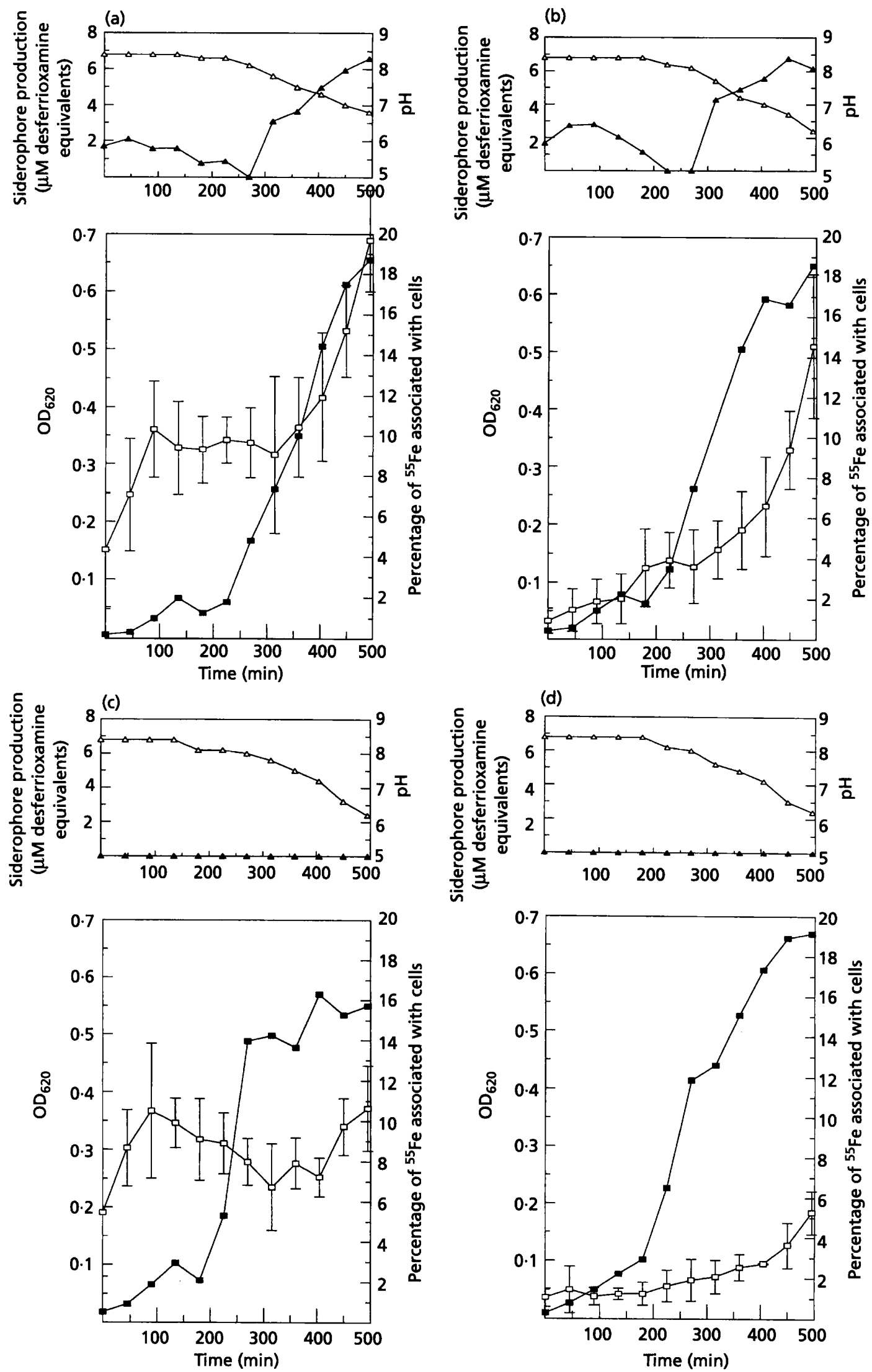

Fig. 2. For legend see facing page. 
end of the experiment, but not as high as when the cells were grown in iron-restricted conditions (Fig. 2a). No siderophore was detected.

When S. aureus was grown in iron-plentiful medium with transferrin inside the dialysis membrane (Fig. 2d), growth was similar to the previous experiments. Radioactivity associated with the cells was low initially, and stayed low with a slight increase towards the end of the experimental period, but not as much as when the cells had direct contact with the transferrin (Fig. 2c) or when they were grown in iron-restricted conditions (Fig. 2b). No siderophore was detected.

Reductase activity was not detected in the supernatant from $8 \mathrm{~h} S$. aureus cultures. No breakdown products of transferrin could be seen on non-denaturing PAGE gels, indicating that the supernatant did not contain protease activity directed toward transferrin.

\section{S. epidermidis}

Uptake experiments conducted over $30 \mathrm{~min}$ with $S$. epidermidis ATCC 14990 produced results very similar to those seen with S. aureus NCTC 8532 in Fig. 1. Uptake was not seen in experiments where labelled transferrin was mixed with SSD-0Fe, although initial cell-associated radioactivity was seen. Supernatants with a $\mathrm{pH}$ of 5.6 caused an increase in uptake, but if the $\mathrm{pH}$ was adjusted to $7 \cdot 4$ this uptake did not occur (data not shown).

S. epidermidis grew poorly in SSD-OFe over $8 \mathrm{~h}$ and growth was not improved when labelled transferrin was added in concentrations containing enough iron to stimulate growth, nor when cultures were grown for up to $24 \mathrm{~h}$. Dialysis membrane did not affect growth. During growth experiments there was some initial radioactivity associated with the cells, similar to the $30 \mathrm{~min}$ experiments. This activity declined and remained constant at approximately $6 \%$, while $\mathrm{pH}$ did not fall below $8 \cdot 0$. No siderophore was detected. If the transferrin was separated from the cells by a dialysis membrane, growth was not affected, but the amount of cell-associated ${ }^{55} \mathrm{Fe}$ was lower and remained constant at approximately $2 \%$.

When S. epidermidis was grown in iron-plentiful medium, growth was much stronger. A high level of radioactivity was associated with the cells ( $11 \%$ within $45 \mathrm{~min}$ ), which slowly increased to $14 \%$ during the course of the experiment. No siderophore was detected. If the transferrin was separated from the cells by a dialysis membrane, the amount of radioactivity associated with the cells remained at less than $2 \%$.

Reductase activity and protease activity directed toward transferrin were not detected in S. epidermidis supernatant.

\section{DISCUSSION}

When Schade (1963) showed that $S$. aureus could grow in serum in vitro, this was evidence that $S$. aureus was able to use iron bound to transferrin as a nutritional iron source. Iron-supplemented serum enabled $S$. aureus to grow better, indicating that the amount of iron taken up from the transferrin was not enough to achieve maximal growth. The results of our experiments support this observation. Uptake of ${ }^{55} \mathrm{Fe}$ bound to transferrin by $S$. aureus occurred, but was delayed and could not be detected in 30 min experiments.

Uptake by $8 \mathrm{~h}$ cultures of growing $S$. aureus cells occurred during the mid- to late-exponential phase. Uptake was regulated by iron since cells grown in iron-plentiful conditions showed much lower levels of cell-associated radioactivity. Uptake did not require direct cell contact since uptake occurred when the transferrin was separated from the cells by a dialysis membrane. This suggests that specific receptors or a transferrin-binding protein, such as that described by Modun et al. (1994), were not responsible for the uptake seen, and that it was mediated via a component of supernatant that was able to pass through a dialysis membrane. CAS activity (siderophore) was produced by $S$. aureus cells immediately prior to uptake of ${ }^{55} \mathrm{Fe}$. Exponential-phase supernatant did not have detectable levels of reducing ability or protease activity. It is therefore likely that the component of supernatant responsible for the uptake of ${ }^{55} \mathrm{Fe}$ bound to transferrin was siderophore. The structure of the siderophore(s) produced by $S$. aureus in this medium is presently unknown, but there is evidence to suggest (Lindsay \& Riley, 1994) that it is not staphyloferrin A described by Meiwes et al. (1990), staphyloferrin B described by Dreschel et al. (1993), or citrate.

Uptake of ${ }^{55} \mathrm{Fe}$ bound to transferrin occurred slowly and only in growing cells after many hours incubation. As the number of cells in the culture increased (Fig. 2a, b), the amount of ${ }^{55} \mathrm{Fe}$ per cell did not increase. Therefore, the uptake detected is not typical of an active process, and is relatively inefficient. This agrees with the observations of Schade (1963) and Brock \& Ng (1983), who showed that $S$. aureus cells did not grow at an efficient rate in serum since growth could be enhanced by adding iron or desferrioxamine. The use of metabolic inhibitors such as $\mathrm{KCN}$ to demonstrate active transport is inappropriate when the test cells are in a growing culture. Attempts to fractionate cells were unsuccessful, and we were unable to demonstrate association of ${ }^{55} \mathrm{Fe}$ with a cytoplasmic fraction.

Schade (1963) also showed that isolates of S. albus (CoNS) were unable to grow in serum that had not been supplemented with iron. Again, our observations support

Fig. 2. Growth ( $\square$; measured as $O D_{620}$ ), uptake of ${ }^{55} \mathrm{Fe}$ bound to transferrin ( $\square$, expressed as percentage of available radioactivity associated with cells), siderophore production ( $\Delta$; expressed in $\mu \mathrm{M}$ desferrioxamine equivalents), and pH $(\triangle)$ of cultures of $S$. aureus NCTC 8532 over $8 \mathrm{~h}$ when grown in: (a) iron-restricted SSD-0Fe with ${ }^{55} \mathrm{Fe}$-transferrin; (b) ironrestricted medium with ${ }^{55} \mathrm{Fe}$-transferrin inside a dialysis membrane; (c) iron-plentiful medium with ${ }^{55} \mathrm{Fe}$-transferrin; and (d) iron-plentiful medium with ${ }^{55} \mathrm{Fe}$-transferrin inside a dialysis membrane. Data shown are the mean of at least three experiments. Standard deviations are indicated for percentage ${ }^{55} \mathrm{Fe}$ uptake. 
these results. S. epidermidis was unable to grow in the presence of ${ }^{55} \mathrm{Fe}$-transferrin. Uptake of ${ }^{55} \mathrm{Fe}$ bound to transferrin was not seen in 30 min experiments nor by growing cells over $8 \mathrm{~h}$, suggesting that $S$. epidermidis cannot use transferrin as an iron source. Siderophore activity, reducing ability or protease activity was not detected in $S$. epidermidis supernatant.

In $30 \mathrm{~min}$ or $8 \mathrm{~h}$ experiments with $S$. aureus or $S$. epidermidis, ${ }^{55} \mathrm{Fe}$ was associated with cells immediately upon contact. This was not regulated by iron concentration and required direct contact between the cells and transferrin. This activity may be due to transferrin binding to the cell surface, although it is unlikely that this binding is associated with ${ }^{55} \mathrm{Fe}$ uptake since $S$. epidermidis exhibits this binding but cannot extract enough ${ }^{55} \mathrm{Fe}$ to stimulate growth. Binding of transferrin to the cell surface could be due to non-specific forces, or binding may be specific and due to a transferrin-binding protein such as that described by Modun et al. (1994). However, the expression of the protein detected by Modun et al. (1994) was regulated by iron in $S$. epidermidis. This was not seen in our experiments.

The effect of $\mathrm{pH}$ on uptake of iron bound to transferrin was highlighted in the 30 min experiments. The affinity of transferrin for iron falls when $\mathrm{pH}$ is lower than 6 . The supernatants with $\mathrm{pH}$ values of 5.4 appeared to enhance uptake of ${ }^{55} \mathrm{Fe}$ bound to transferrin by $S$. aureus and $S$. epidermidis cells in $30 \mathrm{~min}$ experiments. However, this is likely to be due to the reduced affinity of transferrin for iron at low $\mathrm{pH}$, since the effect was abolished if the $\mathrm{pH}$ was raised. Therefore it is very important to monitor $\mathrm{pH}$ in experiments such as these. Growth experiments for extended periods may allow the $\mathrm{pH}$ to drop to levels where it can affect transferrin binding of iron. The experiments of Marcelis et al. (1978) in particular may have been influenced by unchecked $\mathrm{pH}$, as could those of Schade (1963), since the $\mathrm{pH}$ of spent growth medium was not reported.

These experiments were performed in artificial media in vitro and the ability of staphylococci to take up iron bound to transferrin in vivo is unknown. Our results are consistent with Schade's observations when staphylococci were grown in serum in vitro. In the body, transferrin is not the only potential source of bacterial iron. Lactoferrin, an iron-binding protein similar to transferrin, is found in milk, tears and mucus, and also in polymorphonuclear leucocytes, where it is released during inflammation. A human lactoferrin-binding protein produced by $S$. aureus has recently been described (Naidu et al., 1991, 1992), although it has not been established whether this binding is involved in the uptake of iron bound to lactoferrin. The method used in the present study was not successful for measuring uptake of ${ }^{55} \mathrm{Fe}$ bound to lactoferrin, as the protein bound to the cellulose nitrate membranes and a suitable blocking agent could not be found (J. A. Lindsay, unpublished observations). Since haemolysins are produced by many staphylococci, haemoglobin and haem are potential sources of nutritional iron in vivo (Francis et al., 1985). Brock et al. (1991) have suggested that cell-derived iron may be more readily available to staphylococci than iron bound to transferrin. They did not detect significant levels of iron uptake from transferrin. This may have been due to a shorter incubation time $(4.5 \mathrm{~h})$ than the one used in the present study. Differing growth media and levels of iron restriction may also have been important.

Much work is still required to determine which mechanisms for the uptake of iron are possessed by staphylococci and which are activated during infection. Evidence that $S$. aureus is better equipped to handle iron-restriction than $S$. epidermidis is accumulating, including factors such as the ability to survive and grow in serum and in SSD-0Fe, the production of siderophores and iron-regulated proteins in $\mathrm{SSD}-\mathrm{OFe}$, and now the ability to take up iron bound to transferrin in SSD-0Fe. These factors may contribute to the increased pathogenicity of $S$. aureus when compared to S. epidermidis and the other CoNS.

\section{REFERENCES}

Brock, J. H. \& Ng, J. (1993). The effect of desferrioxamine on the growth of Stapbylococcus aureus, Yersinia enterocolitica and Streptococcus faecalis in human serum: uptake of desferrioxamine-bound iron. FEMS Microbiol Lett 20, 439-442.

Brock, J. H., Williams, P. H., Licéaga, J. \& Wooldridge, K. G. (1991). Relative availability of transferrin-bound iron and cellderived iron to aerobactin-producing and enterochelin-producing strains of Escherichia coli and to other microorganisms. Infect Immun 59, 3185-3190.

Courcol, R. J., Lambert, P. A., Fournier, P., Martin, G. R. \& Brown, M. R.W. (1991). Effects of iron depletion and sub-inhibitory concentrations of antibiotics on siderophore production by Stapbylococcus aureus. J Antimicrob Chemother 28, 663-668.

Cowart, R. E. \& Foster, B. G. (1985). Differential effects of iron on the growth of Listeria monocytogenes: minimum requirements and mechanism of acquisition. J Infect Dis 151, 721-730.

Cowart, R. E., Marquardt, M. P. \& Foster, B. G. (1980). The removal of iron and other trace elements from a complex bacteriological medium. Microbios Lett 13, 117-122.

Drechsel, H., Freund, S., Nicholson, G., Haag, H., Jung, O., Zăhner, H. \& Jung, G. (1993). Purification and chemical characterization of staphyloferrin B, a hydrophilic siderophore from staphylococci. BioMetals 6, 185-192.

Francis, R. T., Jr, Booth, J. W. \& Becker, R. R. (1985). Uptake of iron from hemoglobin and the haptoglobin-hemoglobin complex by hemolytic bacteria. Int J Biochem 17, 767-773.

Lindsay, J. A. \& Riley, T. V. (1994). Staphylococcal iron requirements, siderophore production and iron-regulated protein expression. Infect Immun 62, 2309-2314.

Marcelis, J. H., Den Daas-Slagt, H. J. \& Hoogkamp-Korstanje, J. A. A. (1978). Iron requirements and chelator production of staphylococci, Streptococcus faecalis and enterobacteriaceae. Antonie Leeuwenboek 44, 257-267.

Meiwes, J., Fiedler, H.-P., Haag, H., Zăhner, H., Konetschny-Rapp, S. \& Jung, G. (1990). Isolation and characterization of staphyloferrin A, a compound with siderophore activity from Staphylococcus byicus DSM 20459. FEMS Microbiol Lett 67, 201-206.

Modun, B., Kendall, D. \& Williams, P. (1994). Staphylococci express a receptor for human transferrin: identification of a 42 kilodalton cell wall transferrin-binding protein. Infect Immun 62, 3850-3858.

Naidu, A. S., Miedzobrodzki, J., Musser, J. M., Rosdahl, V. T., Hedström, S.-Å. \& Forsgren, A. (1991). Human lactoferrin binding 
in clinical isolates of Staphylococcus aureus. J Med Microbiol 34, 323-328.

Naidu, A. S., Andersson, M. \& Forsgren, A. (1992). Identification of a human lactoferrin-binding protein in Staphylococcus aureus. J Med Microbiol 36, 177-183.

Neuhoff, V., Arold, N., Taube, D. \& Ehrhardt, W. (1988). Improved staining of proteins in polyacrylamide gels including isoelectric focusing gels with clear background at nanogram sensitivity using Coomassie Brilliant Blue G-250 and R-250. Electrophoresis 9, 255-262.

Pfaller, M. A. \& Herwaldt, L. A. (1988). Laboratory, clinical and epidemiological aspects of coagulase-negative staphylococci. Clin Microbiol Rev 1, 281-299.

Schade, A. L. (1963). Significance of serum iron for the growth, biological characteristics, and metabolism of Staphylococcus aureus. Biochemische Zeitschrift 338, 140-148.

Schwyn, B. \& Neilands, J. B. (1987). Universal chemical assay for the detection and determination of siderophores. Anal Biochem 160, $47-56$.

Williams, P. \& Griffiths, E. (1992). Bacterial transferrin receptors structure, function and contribution to virulence. Med Microbiol Immunol 181, 301-322.

Wooldridge, K. G. \& Williams, P. H. (1993). Iron uptake mechanisms of pathogenic bacteria. FEMS Microbiol Rev 12, $325-348$.

Received 6 July 1994; revised 20 September 1994; accepted 13 October 1994. 